\title{
Epidemiological study of wheeze, doctor diagnosed asthma, and cough in preschool children in Leicestershire
}

\author{
David K Luyt, Paul R Burton, Hamish Simpson
}

Abstract

Objective-To determine the cumulative prevalences of wheeze and doctor diagnosed asthma and the point prevalences of recurrent cough and wheeze in children aged 5 years and under.

Design-Questionnaire survey of population based random sample of children registered on regional authority's child health index for immunisation; questionnaire completed by parents.

Setting-Leicestershire.

Subjects-1650 white children born in 1985-9 who were surveyed in 1990 .

Main outcome measures-Cumulative prevalences of wheeze and doctor diagnosed asthma and point prevalences of recurrent cough and wheeze by age and sex.

Results-There were 1422 replies (86.2\%; 726 for boys, 696 for girls). Overall, $11 \cdot 0 \%$ (95\% confidence interval $9 \cdot 4 \%$ to $12 \cdot 6 \%$ ) of children had formally been diagnosed as having asthma, the cumulative prevalence in boys $(12.7 \%)$ being somewhat higher than in girls $(9 \cdot 2 \%)$ (age adjusted odds ratio $1 \cdot 47, p=0 \cdot 03$ ). As expected, the cumulative prevalence of asthma increased significantly with age $(7 \cdot 5 \%(13 / 173)$ in children under 1 year, $15.9 \%(61 / 383)$ in children of 4 years and over; $\mathbf{p}<0.001)$. The cumulative prevalence of wheeze overall was $15 \cdot 6 \%(13 \cdot 7 \%$ to $17 \cdot 5 \%)$, being higher in boys $(17.6 \%)$ than in girls $(13.5 \%)$ (odds ratio $1.38, p=0.03$ ). The overall prevalence of recurrent cough without colds was $21.8 \%(19.6 \%$ to $23.9 \%$ ), with a non-significant excess in boys $(23.1 \%$ $v 20.4 \%$ ). The overall prevalence of wheezing attacks during the previous 12 months was $13.0 \%$ $(11 \cdot 3 \%$ to $14 \cdot 8 \%$ ) with a non-significant excess in boys $(14 \cdot 5 \% v 11 \cdot 5 \%)$.

Conclusions-These findings are baseline results and emphasise the importance of studying the age group of interest rather than relying on the recall of parents of school age children.

\section{Introduction}

Estimates of the prevalence of asthma in childhood are higher in developed countries ${ }^{1-3}$ than in developing areas of the world. The lack of an agreed definition for asthma ${ }^{4-6}$ leads to inconsistent diagnostic practices, ${ }^{7-10}$ which may partially explain these differences. The prevalence of the underlying symptoms of asthma ${ }^{112}$ reflect the prevalence of the disease but are potentially more reliable. ${ }^{13}$

In Westernised countries results from community based studies ${ }^{1419}$ and trends in admission to hospital ${ }^{20-22}$ suggest that the prevalence of asthma in children has increased. Most children with asthma develop symptoms before the age of 5 years. ${ }^{23-27}$ Studies in children of this age are potentially flawed as they are based largely on parental recall during the course of prevalence studies in school age children. ${ }^{23} 28 \mathrm{We}$ therefore investigated the cumulative prevalences of wheeze and asthma as diagnosed by a doctor in preschool children and the point prevalences of recurrent cough and wheeze within the previous 12 months.

\section{Subjects and methods}

The subjects were white children aged 5 years and under who lived in Leicestershire. They were recruited as a stratified random sample from the population, the sampling frame being Leicestershire Regional Health Authority's child health index. This index is a constantly updated computer record of all children who were born and who live in Leicestershire. Stratification was by year of birth to ensure equal representation of each year cohort from 1985 to 1989.

The sample size was calculated using standard sample size calculations. ${ }^{29}$ Assuming a prevalence of recurrent wheeze in the population of about $20 \%, 121719$ we calculated that a sample size of 1000 would be required to be $95 \%$ certain of estimating an overall prevalence in the sample within a mean of $2 \cdot 5 \%$ of its true value. Assuming that a minimum response rate would be $60 \%$, we therefore posted questionnaires (including a postage paid envelope) to the parents of 1650 children. Non-responders were sent the questionnaire twice more. The three mailings took place between April and July 1990.

\section{QUESTIONNAIRE DESIGN}

As there was no suitable and well validated questionnaire for use in this age group, an appropriate questionnaire was constructed to address the study objectives. When possible the questions were abstracted from previously validated questionnaires. ${ }^{30-34}$ An introductory letter explaining the nature of the study and containing detailed instructions on how to complete the questionnaire was included as the front page of the document. The questionnaire comprised three sections with a total of 51 questions. The first section dealt with the nature of respiratory history and symptomswheeze, cough, and doctor diagnosed asthma. The second examined putative environmental factors within and outside the home. The third dealt largely with the family's social status and history of atopy.

Wheeze was elicited by the question "Has your child ever had attacks of wheezing?" This section of the questionnaire was introduced by an explanatory paragraph defining wheeze as "breathing that makes a high pitched musical sound from the chest, not the throat." Parents who answered positively to the key question were then asked about 10 features of the wheeze, including the age of onset and the time since the last attack.

The presence of doctor diagnosed asthma was elicited by the question "Has a doctor told you that (s)he has asthma or bronchitis?" As the terms asthma and bronchitis are often applied interchangeably in children under 5 years old and their treatment is similar, we thought that a positive response to this question justified the use of the phrase doctor diagnosed asthma. Inquiry was then made about the age at diagnosis. The key questions on wheeze and asthma were separated to avoid giving parents the impression that there need necessarily be a relation between the two. Three questions related to abnormal coughing. Parents were asked "Does (s)he usually have a cough with colds?" and "Does (s)he have a cough without colds?" The third question concerned nocturnal cough.
Professor H Simpson Health. 
A small pilot study of 150 questionnaires was carried out before starting the main study, and no serious problems were encountered. Approval for the study was obtained from the Leicestershire Health Authority's ethical committee.

\section{REPEATABILITY TESTING}

We tested repeatability of the questionnaire by sending it again to 100 randomly selected respondents six months after the initial survey. We explained to parents that the repetition was a form of quality control for the study and not a check on their answers.

\section{STATISTICAL ANALYSIS}

Statistical analysis was performed largely with SAS $^{35}$ and generalised linear interactive modelling, version 3.77. ${ }^{36}$ Categorical data were analysed using contingency tables, hypothesis testing being based on the $\chi^{2}$ test for homogeneity without continuity correction or, when applicable, the $\chi^{2}$ test for trend. When appropriate linear modelling took the form of unconditional logistic regression, formal hypothesis testing being based on the likelihood ratio test. ${ }^{37}$ Age on the date of completion of the questionnaire was modelled as an ordinal variable taking values between 0 (under 1 year) and 4 ( 4 years and over), thus permitting full tabulation of the data on which the models were constructed. A second series of models was constructed using exact age in decimal years, but the principal inferences were identical and these results are not therefore reported. All models were subjected to standard model checking procedures, including tests for non-linearity and interaction, the analysis of Pearson residuals, and the investigation of regression leverage. ${ }^{37}$ All reported models provided an adequate fit to the observed data. Survival functions were constructed by the method of Kaplan and Meier and were compared with the log rank test. ${ }^{38}$

Repeatability of questionnaire replies was assessed by percentage agreement and more formally with Cohen's K statistic. ${ }^{39}$

\section{Results}

RESPONSE RATE

A total of 1650 questionnaires was posted and 1422 were returned, a response rate of $86 \cdot 2 \%$. The response rate was similar in each age group and for both sexes. The total sample comprised $726(51 \cdot 0 \%)$ boys and 696 $(49 \cdot 0 \%)$ girls.

\section{REPRESENTATIVENESS OF REPLIES}

The representativeness of the study sample was assessed by reference to existing data on population distribution in Leicestershire (Leicestershire District Health Authority, birth notification computer tape, 1987)..$^{40}$ The geographical distribution of site of residence was similar to the equivalent distribution of live white births in 1987 (Leicestershire District Health Authority, birth notification computer tape, 1987), and the social class distribution $(30.4 \%$ in classes 1 and $2,44.3 \%$ in class 3 , and $25 \cdot 3 \%$ in classes 4 and 5 ) was not unlike that of the 1981 census $(26 \cdot 2 \%, 47 \cdot 8 \%$, and $25.9 \%$ respectively)..$^{40}$

Parents of children with symptoms might be more likely to return a completed questionnaire. To investigate this issue symptom prevalence was compared across the three mailings (table I). No significant trends were observed, suggesting that the results of the study were probably not distorted.

Eighty nine per cent of questionnaires (1255) were completed by the mother, $8.4 \%$ (119) by the father, and $2 \cdot 5 \%$ (35) by both. The prevalences of symptoms were uniformly but insignificantly $(p>0.2)$ higher when the questionnaire was answered by the mother
TABLE I-Prevalences of symptoms by mailing of questionnaire. Values are numbers (percentages)

\begin{tabular}{lcrrr}
\hline Mailing & $\begin{array}{c}\text { No of } \\
\text { replies }\end{array}$ & Wheeze & $\begin{array}{c}\text { Doctor } \\
\text { diagnosed } \\
\text { asthma }\end{array}$ & $\begin{array}{c}\text { Recurrent cough } \\
\text { without colds }\end{array}$ \\
\hline First & 1213 & $195(16 \cdot 1)$ & $131(10 \cdot 8)$ & $175(14 \cdot 4)$ \\
Second & 162 & $22(13 \cdot 6)$ & $18(11 \cdot 1)$ & $23(14 \cdot 2)$ \\
Third & 47 & $5(10 \cdot 6)$ & $7(14 \cdot 9)$ & $11(23 \cdot 4)$ \\
\hline
\end{tabular}

rather than the father, and they were highest when the questionnaire was answered by both parents. These differences should not have biased the results of the study.

Thus, by the criteria described, the study sample was considered representative of children of 5 and under in Leicestershire.

\section{REPEATABILITY}

The key questions on wheeze and doctor diagnosed asthma were highly repeatable (table II). The results for cough should be interpreted with caution, although its poor repeatability may simply reflect seasonal variation (see discussion).

TABLE II-Measures of repeatability of answers to questions of questionnaire

\begin{tabular}{lll}
\hline Question & \multicolumn{2}{l}{ Cohen's K Agreement (\%) } \\
\hline $\begin{array}{l}\text { Has your child ever had attacks of wheezing? } \\
\text { Has your child had any attacks of wheezing }\end{array}$ & 0.88 & 97 \\
$\quad$ during the past 12 months? & 0.79 & 97 \\
$\begin{array}{l}\text { Has a doctor told you that (s)he has asthma or } \\
\text { bronchitis? }\end{array}$ & 0.82 & 96 \\
$\begin{array}{l}\text { Does (s)he usually have a cough with colds? } \\
\text { Does (s)he usually have a cough without colds? }\end{array}$ & 0.53 & 78 \\
$\begin{array}{l}\text { Does (s)he see a doctor for wheezing or asthma? } \\
\text { Has (s)he ever taken medicine for wheezing or }\end{array}$ & 0.65 & 82 \\
$\quad$ asthma? & 0.74 & 96 \\
$\begin{array}{l}\text { Has (s)he ever been admitted to hospital for } \\
\text { wheezing or asthma? }\end{array}$ & 0.85 & 99 \\
\hline
\end{tabular}

\section{CUMULATIVE AND POINT PREVALENCES}

The overall cumulative prevalences of doctor diagnosed asthma and symptomatic wheeze were $11.0 \%$ (95\% confidence interval $9 \cdot 4 \%$ to $12.6 \%$ ) and $15.6 \%$ $(13 \cdot 7 \%$ to $17 \cdot 5 \%)$ respectively. Table III shows these data by sex and age.

The cumulative prevalence of diagnosed asthma increased systematically and significantly with age $(p=$ 0.0002 ). Boys had a consistently higher cumulative incidence of doctor diagnosed asthma in all age groups

TABLE III-Cumulative prevalences of doctor diagnosed asthma and symptomatic wheeze by age group and sex

\begin{tabular}{llcc}
$\begin{array}{l}\text { Age group } \\
\text { (years) }\end{array}$ & $\begin{array}{c}\text { No with } \\
\text { symptoms }\end{array}$ & No in group & $\begin{array}{c}\text { Cumulative prevalence } \\
(95 \% \text { confidence } \\
\text { interval })(\%)\end{array}$ \\
\hline
\end{tabular}

Boys:

$<1$

$1-2$
$2-3$
$3-4$

$3-4$
$\geqslant 4$

Girls:

$<1$
$1-2$
$2-3$

$2-3$
$3-4$
$\geqslant 4$

Boys:

Boys:
$<1$
$1-2$

1-2

$2-3$
$3-4$
$\geqslant 4$

$\geq 4$
Girls:

Girls:
$<1$

$<1$
$1-2$
$2-3$

$3-4$
$\geqslant 4$
Doctor diagnosed asthma

\begin{tabular}{|c|c|c|}
\hline 9 & 99 & $9.1 \quad(3.4$ to 14.8$)$ \\
\hline 16 & 160 & $10.0(5.4$ to $14 \cdot 6)$ \\
\hline 17 & 127 & $13.4(7.5$ to 19.3$)$ \\
\hline 12 & 142 & $8.5(3.9$ to 13.0$)$ \\
\hline 38 & 196 & $19.4(13.9$ to 24.9$)$ \\
\hline 4 & 74 & $5.4(0.3$ to 10.6$)$ \\
\hline 7 & 146 & $4.8(1.3$ to 8.3$)$ \\
\hline 10 & 138 & $7.2(2.9$ to 11.6$)$ \\
\hline 20 & 151 & $13.2(7.8$ to 18.7$)$ \\
\hline 23 & 187 & $12.3(7.6$ to 17.0$)$ \\
\hline & Wheeze & \\
\hline 20 & 99 & $20.2(12.3$ to 28.1$)$ \\
\hline 29 & 160 & $18 \cdot 1(12.2$ to $24 \cdot 1)$ \\
\hline 23 & 127 & 18.1 (11.4 to 24.8$)$ \\
\hline 20 & 142 & 14.1 (8.4 to 19.8$)$ \\
\hline 36 & 198 & $18.2(12.8$ to 23.6$)$ \\
\hline 7 & 74 & $9.5(2.8$ to $16 \cdot 1)$ \\
\hline 12 & 146 & $8.2(3.8$ to 12.7$)$ \\
\hline 20 & 138 & $14.5(8.6$ to 20.4$)$ \\
\hline 25 & 151 & 16.6 (10.6 to 22.5$)$ \\
\hline 30 & 187 & $16.0(10.8$ to 21.3$)$ \\
\hline
\end{tabular}


with the exception of 3-4 years. A logistic regression model was created by taking the number of diagnosed cases of doctor diagnosed asthma in each age-sex group as the binomial numerator and the total number of children in the respective groups as the denominator. After adjustment for the effect of age the odds ratio for the diagnosis of asthma (boys:girls) was 1.47 (1.05 to $2.06)(p=0.03)$. After adjustment for the effect of sex the cumulative prevalence of doctor diagnosed asthma still increased with age $(p=0.0001)$, the estimated multiplicative increase being $1.27(1.12$ to 1.45$)$ for each additional year of age.

By definition, the cumulative prevalence of wheeze should also have increased systematically with age (table III) unless there was a strong birth cohort effect. Overall, however, the cumulative incidence of wheeze remained remarkably constant with age, being $15.6 \%$ $(27 / 173)$ in children under 1 year, $13.4 \%(41 / 306)$ in those aged $1-2$ years, $16 \cdot 2 \%(43 / 265)$ in those aged $2-3$ years, $15.4 \%(45 / 293)$ in those aged $3-4$ years, and $17 \cdot 1 \%(66 / 385)$ in those of 4 years and over. As with doctor diagnosed asthma, sex had a strong effect, the odds of wheeze in boys being an estimated 1.38 (1.03 to $1.84)$ times higher than that in girls $(p=0.03)$.

Interestingly, these overall data obscured an important interaction $(p=0.03)$ : whereas the reported cumulative prevalence of wheeze was reasonably constant (or slowly falling) with age in boys, it increased somewhat in girls; the estimated multiplicative annual increase in the odds ratio was 1.21 (1.03 to $1 \cdot 44)$.

The finding that the proportion of children reported to have ever wheezed was relatively constant with year of birth may indicate that parental perception of significant wheeze is transient and that symptoms that seem relevant to the parent of a young child rapidly fade from memory as the child gets older. This view is supported by the birth cohort specific Kaplan-Meier functions illustrating the cumulative probability of being perceived to have developed wheeze with increasing age (figure). Clearly, the apparent rate of development of wheeze varies strongly and systematically with age (test for homogeneity: $\chi^{2}{ }_{4}=30 \cdot 5, p=$
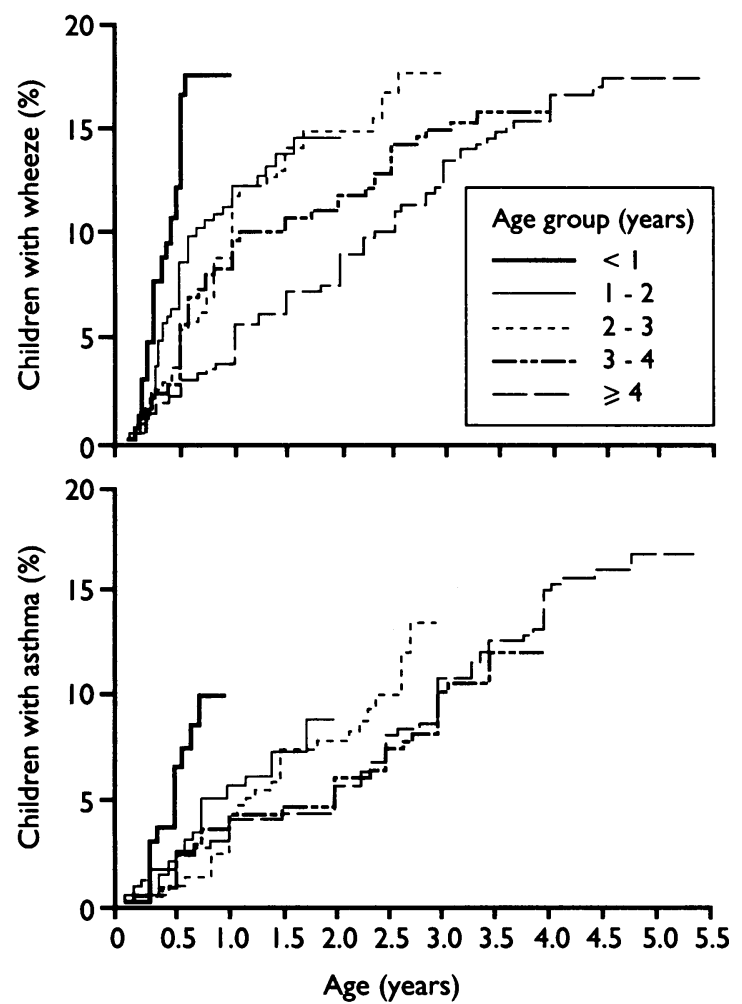

Cumulative probability of being perceived as having developed wheeze and asthma by age group
TABLE IV-Prevalences of recurrent cough without colds and of at least one wheezing attack during previous 12 months by age group and sex

\begin{tabular}{|c|c|c|c|}
\hline $\begin{array}{l}\text { Age group } \\
\text { (years) }\end{array}$ & No with symptoms & No in group & $\begin{array}{c}\text { Prevalence } \\
\text { (95\% confidence } \\
\text { interval) }(\%)\end{array}$ \\
\hline \multicolumn{4}{|c|}{ Cough } \\
\hline \multicolumn{4}{|l|}{ Boys: } \\
\hline$<1$ & 17 & 97 & $17.5(10.0$ to 25.1$)$ \\
\hline $1-2$ & 29 & 160 & $18 \cdot 1(12 \cdot 2$ to $24 \cdot 1)$ \\
\hline $2-3$ & 30 & 127 & $23.6(16.2$ to 31.0$)$ \\
\hline $3-4$ & 35 & 140 & $25.0(17.8$ to 32.2$)$ \\
\hline$\geqslant 4$ & 55 & 196 & $28.1(21.8$ to 34.4$)$ \\
\hline \multicolumn{4}{|l|}{ Girls: } \\
\hline$<1$ & 15 & 72 & $20.8(11.5$ to 30.2$)$ \\
\hline $1-2$ & 22 & 146 & $15.1(9.3$ to 20.9$)$ \\
\hline $2-3$ & 19 & 137 & $13.9(8.1$ to 19.7$)$ \\
\hline $3-4$ & 35 & 151 & $23.2(16.4$ to 29.9$)$ \\
\hline$\geqslant 4$ & 50 & 184 & $27.2(20.7$ to 33.6$)$ \\
\hline \multicolumn{4}{|c|}{ Wheeze in previous 12 months } \\
\hline \multicolumn{4}{|c|}{ (1) } \\
\hline$<1$ & 20 & 99 & $20 \cdot 2(12.3$ to $28 \cdot 1)$ \\
\hline $1-2$ & 28 & 160 & 17.5 (11.6 to 23.4$)$ \\
\hline $2-3$ & 17 & 127 & $13.4(7.5$ to 19.3$)$ \\
\hline $3-4$ & 13 & 142 & $9.2(4.4$ to 13.9$)$ \\
\hline$\geqslant 4$ & 27 & 198 & $13.6(8.9$ to 18.4$)$ \\
\hline \multicolumn{4}{|r|}{ (1) } \\
\hline$<1$ & 7 & 74 & \\
\hline $1-2$ & 12 & 146 & 8.2 (3.8 to 12.7$)$ \\
\hline $2-3$ & 16 & 138 & $11.6(6.3$ to 16.9$)$ \\
\hline $3-4$ & 21 & 151 & $13.9(8.4$ to 19.4$)$ \\
\hline$\geqslant 4$ & 24 & 187 & $12.8(8.0$ to 17.6$)$ \\
\hline
\end{tabular}

0.0001 ; test for linear trend: $\chi_{1}^{2}=20.6, p<0.0001$ ). Thus, parents of very young children seemed to be more likely than parents of older children to report that their child had developed wheeze during the early years of life. Interestingly, the age specific KaplanMeier survival functions for the cumulative probability of being diagnosed as having asthma also showed an equivalent pattern (test for homogeneity: $\chi^{2}{ }_{4}=18 \cdot 6$, $\mathrm{p}=0.0009$; test for linear trend: $\chi^{2}{ }_{1}=9.7, \mathrm{p}=0.002$ ), although the observed effect was rather less strong (figure).

The evidence for non-homogeneity of the age specific patterns of the reported prevalence of wheeze was much stronger in boys $\left(\chi_{4}^{2}=27 \cdot 7, p=0.0001\right)$ than in girls $\left(\chi_{4}^{2}=5 \cdot 0, p=0 \cdot 29\right)$. The non-homogeneity of the functions for doctor diagnosed asthma was, however, only slightly greater in boys $\left(\chi_{4}^{2}=11 \cdot 8, \mathrm{p}=0.02\right)$ than girls $\left(\chi_{4}^{2}=10 \cdot 4, p=0 \cdot 03\right)$.

The prevalence of recurrent cough increased significantly with age (table IV) $(p=0.0003)$, the odds increasing by an estimated multiplicative factor of $1 \cdot 19$ (1.08 to 1.31$)$ for each additional year of age. When age was taken into account the odds of recurrent cough in boys was an estimated 1.18 times greater $(0.92$ to 1.53$)$ than that in girls $(p=0 \cdot 19)$.

Overall, boys had a higher odds of having had a wheezing attack during the previous 12 months $(\mathrm{p}=$ $0 \cdot 10)$, the estimated sex ratio being $1.30(0.95$ to $1 \cdot 77)$. Like the cumulative prevalence of wheeze, the overall prevalence remained reasonably constant with age: $15 \cdot 6 \%(27 / 173)$ in children under 1 year, $13 \cdot 1 \%(40 / 306)$ in those aged $1-2$ years, $12 \cdot 5 \%(33 / 265)$ in those aged $2-3$ years, $11.6 \%(34 / 293)$ in those aged $3-4$ years, and $13.2 \%(51 / 285)$ in those aged 4 years and over. There was also a strong interaction between the effects of age and sex $(p=0.02)$ : in boys the prevalence fell with age at an estimated multiplicative rate of $0.86(0.74$ to 1.00$)$ a year while in girls it was estimated to increase at a multiplicative rate of $1.14(0.95$ to 1.36$)$ a year. These conclusions were unaffected by removing from the analysis children under the age of 1 year, for whom symptoms in the previous 12 months has a modified interpretation.

Of the 156 children who had been diagnosed as having asthma, $72(46 \cdot 1 \%)$ had a history of wheeze without recurrent cough, $17(10.9 \%)$ had recurrent cough without wheeze, $53(34.0 \%)$ had both symptoms, and $14(9.0 \%)$ had neither. Most children with asthma suffered from recurrent cough but only when they had 
a cold. There was no significant sex difference in the symptomatic pattern of those with doctor diagnosed asthma $(p=0 \cdot 19)$. However, the proportion of children with wheeze who had been diagnosed as having asthma increased significantly with increasing age $(40 \cdot 7 \%$ (11/27), 43.9\% (18/41), 48.8\% (21/43), 55.6\% (25/45), and $75.8 \%(50 / 66) ; \mathrm{p}=0.0001)$, as did the equivalent proportions of children with cough $(9.4 \%$ (3/32), $15 \cdot 7 \%$ ( $8 / 51), 22 \cdot 5 \%$ (11/49), $24 \cdot 3 \%$ (17/70), and $29 \cdot 8 \%(31 / 104) ; \mathrm{p}=0.005)$.

\section{Discussion}

Inferences about the prevalence and severity of asthma in preschool children have been based on studies in older age groups ${ }^{14} 19$ and are limited by imperfect recall of asthmatic symptoms. ${ }^{25}$ Sound epidemiological data from studies of preschool children are lacking. Accordingly, we designed, tested, and used a postal questionnaire for parents to investigate a wide range of issues pertaining to asthma in preschool children. We estimated age and sex specific cumulative prevalences and point prevalences of selected asthmatic symptoms and doctor diagnosed asthma. We do not claim that doctor diagnosed asthma is the reference standard for true asthma, but we believe that it is a useful variable with important implications for health care and epidemiology.

\section{VALIDITY OF STUDY}

The study population consisted of a stratified random sample from Leicestershire health authority's child health register, which is an active computer record of all children resident in Leicestershire. This register provides the basis for developmental surveillance and for the immunisation and vaccination programme in the district, and nearly all children of preschool age are said to be registered. Sampling was based on pseudorandom numbers generated by computer. Therefore no reason is apparent why the children selected for the initial mailing should be anything other than representative of the preschool population of Leicestershire.

The overall response rate in the study was $86 \%$, which compares favourably with several other studies of asthma ${ }^{123341}$ in children of school age. We considered the possibility that the responders were a non-random subsample of the mailed population. The parents of children with asthmatic symptoms or diagnosed asthma might have been systematically more (or less) likely to respond than the parents of asymptomatic children. In reality, parents of children with asthma are more likely to respond, but even in the most extreme case-if all of the non-responding parents had symptom free children-the rates we found would have been inflated only by about $16 \%(100 / 86=1 \cdot 16)$. We elected not to seek information from other sources (such as general practitioners) about our nonresponders, partly because we thought that parents' failure to respond to three mailings might reasonably be viewed as an implicit refusal to include their child in the study. To gain some impression of the likely impact of non-response bias we therefore compared the cumulative prevalence and prevalence estimates across the three mailings. As there was no clear pattern to the relation between symptoms and mailing the $14 \%$ nonresponse rate is unlikely to have had any major impact on the principal estimates reported in the study. This conclusion is further supported by the demographic similarity of the responding population to the overall preschool population in Leicestershire.

The validity of the pertinent questions in the questionnaire should also be considered. When possible these questions were obtained from previously validated questionnaires, and all were piloted to ensure apparent comprehensibility. All questions seemed to have face validity, and informal tests of construct validity showed no serious inconsistency between the results of related questions. Repeatability was tested formally six months after the initial questionnaires were posted. All responses pertaining to wheeze and doctor diagnosed asthma were highly repeatable, confirming previous reports in older children. ${ }^{1233}$ However, the answers to the questions about cough showed moderate or low repeatability. By choosing to test repeatability at six months, the results could have been influenced by seasonal variation. Because of their phrasing, the questions on cough are most likely to have been influenced by this effect. Interestingly, in the cohort component of our study, in which we are following up children between two and five years after the initial survey, preliminary results suggest that the long term repeatability of the questions about cough is higher than the repeatability at six months, which is consistent with this hypothesis. In addition to repeatability, the accuracy of data entry was formally checked by re-entering a total of 25 randomly selected questionnaires. No data errors were identified.

On the basis of these epidemiological conclusions, we believe that our results provide an acceptable reflection of the true, parentally perceived, age and sex specific cumulative prevalence of doctor diagnosed asthma and the prevalence of asthmatic symptoms among preschool children in Leicestershire. These data should therefore be a useful baseline for future comparative studies.

\section{IMPLICATIONS}

Our study also shows that parental recall of the development of symptomatic wheeze is inconsistent even within the preschool age range. Given that there is no effect of birth cohort-which would need to be so large as to be virtually inconceivable over only five years-the fact that the parents of very young children report a similar cumulative prevalence of wheeze to the parents of older children strongly suggests that some episodes of wheeze that are perceived as significant by the parents of the younger children are forgotten as the child gets older. It is not just that parents forget when a child started to wheeze, for that would affect the Kaplan-Meier incidence functions but not the cumulative prevalences themselves, but that parents of older children completely forget episodes of wheeze that the parents of younger children perceive as important. This underlines the difficulty of studying the symptomatic profile of preschool children from the retrospective recall of the parents of school age children.

Our results suggest that many young children might transiently be viewed as having significant symptomatic wheeze but the symptoms are ultimately so shortlived and mild that they are later completely forgotten. This suggests the existence of a pool of wheezing of questionable significance that could potentially contribute to an apparent increase in the prevalence of asthma should an increase in diagnostic vigour and heightened public awareness suddenly lead to such children being diagnosed as asthmatic.

Clearly, if preschool children pass through phases of wheezing and non-wheezing and if parental recall is flawed asthma can be studied comprehensively only in an appropriate age group and ideally by studies with a prospective cohort design. We have extended our cross sectional study to follow a proportion of children longitudinally, and we are aware of a number of other preschool cohorts that are being followed prospectively from birth. We hope that these studies will ultimately help provide definitive answers to the important questions about the development and natural course of asthma and asthmatic symptoms in preschool children. 
CONCLUSIONS

In conclusion, we believe that we have obtained valid estimates of the age and sex specific cumulative prevalences of wheeze and doctor diagnosed asthma and the point prevalences of wheeze and recurrent cough in preschool children. These data are interesting in their own right and should be a valuable comparative baseline for studies in other areas and for investigations of the changes in the incidence and prevalence of asthma over calendar time.

We thank Leicestershire District Health Authority for allowing us to use the child health register as a sampling frame, particularly Dr Barbara Marshall for helping us with this process. We also thank the parents of children volunteered for the study for their cooperation. This work was supported by a grant from Fisons Pharmaceuticals.

1 Gregg I. Epidemiological aspects. In: Clark T, Godfrey S, eds. Asthma. 2nd ed London: Chapman and Hall, 1983:242-78.

2 Anderson HR. The epidemiological and allergic features of asthma in the New Guinea Highlands. Clinical Allergy 1974;4:171-83.

3 Van Niekerk CH, Weinberg EG, Shore SC, Heese HdeV, Van Schalkwyk DJ. Prevalence of asthma: a comparative study of urban and rural Xhos children. Clinical Allergy 1979;9:319-24.

4 Gregg I. Epidemiological research in asthma: the need for a broad perspective. Clinical Allergy 1986;16:17-23.

5 Sibbald B. Genetic basis of asthma. Seminars in Respiratory Medicine 1986;7: 307-15.

6 Samet JM. Epidemiological approaches for the identification of asthma. Ches 1987;91:74-89S.

7 Marks DE, Hillier VF. General practitioners' views of asthma in childhood. $B M F$ 1983;287:949-51.

8 Levy M, Bell L. General practice audit of asthma in childhood. $B M \Im$ 1984;289:1115-6.

$9 \mathrm{Hart} J \mathrm{~T}$. Wheezing in young children: problems of measurement and management. $\Im$ R Coll Gen Pract 1986;36:78-81.

10 Jones A, Sykes A. The effect of symptom presentation on delay in asthma diagnosis in children in a general practice. Respir Med 1990;84:139-42.

11 Andrae S, Axelson O, Bjorksten B, Fredriksson M, Kjellman N-IM. Symptoms of bronchial hyperreactivity and asthma in relation to environmental factors. Arch Dis Child 1988;63:473-8.

12 Clifford RD, Radford M, Howell JB, Holgate ST. Prevalence of respiratory svmptoms among 7 and 11 year schoolchildren and association with asthma. Arch Dis Child 1989;64:1118-25.

13 Lee DA, Winslow NR, Speight ANP, Hey EN. Prevalence and spectrum of asthma in childhood. BMF 1983;186:1256-8.

14 Fleming DM, Crombie DL. Prevalence of asthma and hay fever in England and Wales. BMY 1987;294:279-83.
5 Burr ML. Is asthma increasing? F Epidemiol Community Health 1987;41:185-9. 16 Burney PGJ, Chinn S, Rona RJ. Has the prevalence of asthma increased in children? Evidence from the national study of health and growth 1973-86. $B M 7$ 1990;300:1306-10

17 Burr ML, Butland BK, King S, Vaughan-Williams E. Changes in asthma prevalence: two surveys 15 years apart. Arch Dis Child 1989;64:1452-6.

18 Dawson B, Horobin G, Illsley R, Mitchell R. A survey of childhood asthma in Aberdeen. Lancet 1969;i:827-30.

19 Ninan TK, Macdonald L, Russell G. Changes in the prevalence of respiratory symptoms: two surveys 25 years apart. Thorax 1991;46:322P.

20 Anderson HR. Increase in hospitalisation for childhood asthma. Arch Dis Child 1978;53:295-300.

21 Mitchell EA. International trends in hospital admission for childhood asthma Arch Dis Child 1985;60:376-8.

22 Halfon N, Newacheck PW. Trends in hospitalisation for acute childhood asthma, 1970-84. Am f Public Health 1986;76:1308-11.

$23 \mathrm{NcNicol} \mathrm{KN}$, Williams HB. Spectrum of asthma in children. I. Clinical and physiological components. $B M \mathcal{F}^{1} 1973$;iv:7-11.

24 Blair H. Natural history of childhood asthma. Arch Dis Child 1977;52:613-9.

25 Strachan DP. The prevalence and natural history of wheezing in early childhood. $f R$ Coll Gen Pract 1985;4:182-4.

26 Anderson HR, Bland JM, Patel S, Peckham C. The natural history of asthma in childhood. F Epidemiol Community Health 1986;40:121-9.

27 Morrison-Smith J. The prevalence of asthma and wheezing in children. British Journal of Diseases of the Chest 1976;70:73-7.

28 Aberg N, Engstrom I. Natural history of allergic diseases in children. Acto Paediatr Scand 1990;79:206-11.

29 Armitage P, Berry G, Stapstich L. Methods in medical research. 2nd ed. Oxford: Blackwell Scientific, 1987

30 Gibson HB, Silverstone H, Gandevia B, Hall GJ. Respiratory disorders in seven-year-old children in Tasmania: aims, methods and administration of the survey. Med I Aust 1969:210-5.

31 Ferris BG. Epidemiological standardization project. Am Rev Respir Dis $1978 ; 118: 1-120$

32 Strachan DP, Elton RA. Relationship between respiratory morbidity in children and the home environment. Fam Pract 1986;3:137-42.

33 Salome CM, Peat JK, Britton WJ, Woolcock AJ. Bronchial hyperresponsiveness in two populations of Australian schoolchildren. I. Relation to respiratory symptoms and diagnosed asthma. Clinical Allergy 1987;17 271-81

34 Bumey PGJ, Chinn S. Developing a new questionnaire for measuring the prevalence and distribution of asthma. Chest 1987;91:79-83S

35 SAS Institute. North Caroline: SAS Institute, 1985.

36 Aitkin M, Anderson D, Francis B, Hinde J. Statistical modelling in GLIM. Oxford: Oxford University Press, 1989.

37 McCullagh P, Nelder JA. Generalized linear models. 2nd ed. London: Chapman and Hall, 1989.

38 Miller RG, Gong G, Munoz A. Survival analysis. New York: Wiley, 1981.

39 Abrahamson JII. Making sense of data. Oxford: Oxford University Press, 1988.

40 Office of Population Censuses and Surveys. Census 1981. County repon. Leicestershire part 2. $10 \%$ sample. London: HMSO, 1982.

41 Hill RA, Standen PJ, Tattersfield AE. Asthma, wheezing and school absence in primary schools. Arch Dis Child 1989;64:246-51.

(Accepted 25 March 1993)

\section{A MEMORABLE PATIENT}

\section{Cruel coincidence}

One sunny afternoon in June a young girl was brought into the emergency department after being knocked from her bicycle by a car. She was apnoeic on arrival and had been unresponsive since the accident. I intubated her and put her on a mechanical ventilator. This act produced menacing but silent criticism: she would be brain damaged if she survived the misplaced enthusiasms of a young doctor was the clear but silent message. But I could not abandon this fledgling life to the cruel whim of a road traffic accident and continued to resuscitate her. All investigations gave normal results. She had no obvious injuries, not even a skull fracture. Her body was unmarked, yet she lay there as if sleeping. We transferred her to the intensive care unit, where she remained unsedated and unresponsive.

She was clearly brain stem dead. On a bank holiday weekend it became my responsibility to find a consultant not involved with the case who would confirm this opinion. The first consultant I telephoned refused to come in from home on a holiday weekend to attend a patient who did not require treatment. He was not on duty, and he did not consider the confirmation of brain death to be an emergency. I tried several other consultants and received many different excuses, only some of which seemed to be genuine. Meanwhile, her parents waited and wondered what was delaying the moment of their ultimate anguish when their only daughter would die and her declared wish of being a kidney donor would be fulfilled.

A lovely summer's day gave way to dusk when I rang a senior consultant at home. His daughter said that he was

enjoying a rare night off and had left for a dinner engagement. I persuaded her to give me the number. I waited, then rang, summoning him from the table and explaining the situation. By now I was prepared to endure the wrath of a doctor I knew by repute but had never met. When I had finished my story I started to receive what I at first believed to be another excuse. He had enjoyed a couple of drinks but was not drunk. But he never drove when he had taken any alcohol. He said that he would ask another guest to drive him to the hospital. He arrived in full evening dress and completed the examination thoroughly and quietly. He never once commented on my calling him and made only a few gentle but critical remarks about his colleagues.

When the transplant team arrived in the early hours of the morning and they made their pragmatic but brutal cruciate incision into the abdomen I watched in terror lest the kiss of the surgeon's knife wake this beauty from her sleep. It did not.

The necropsy showed a brainstem haemorrhage. The transplant team told me some time later that one kidney had been sent to Europe and the other, quite by chance, had been implanted into a patient who lived near the donor. It was, apparently, the child of the consultant I had rung first.-A D REDMOND is a senior lecturer in emergency and disaster medicine in Stoke-on-Trent.

We welcome contributions to fillers: $A$ patient who changed my practice; $A$ paper that changed my practice; $A$ memorable patient The message I would most like to leave behind, or similar topics. 